\title{
SIKAP MAHASISWA ASING TERHADAP PROGRAM PEMBELAJARAN BAHASAN INDONESIA BAGI PENUTUR ASING (BIPA)
}

\author{
Rahmat Nasrullah ${ }^{1}$; Titin Rahmiatin ${ }^{2}$ \\ ${ }^{12}$ Program Studi Pendidikan Bahasa Inggris, Fakultas Keguruan dan Ilmu Pendidikan Universitas \\ Muhammadiyah Kendari \\ e-mail: *rahmat.nasrullah@umkendari.ac.id, titinrahmiatin19@gmail.com
}

\begin{abstract}
ABSTRAK: Program pembelajaran Bahasa Indonesia bagi Penutur Asing merupakan salah satu program pembelajaran yang diatur oleh pemerintah dan beberapa institusi di Indonesia. Universitas Muhammadiyah Kendari sebagai salah satu universitas yang memiliki mahasiswa Internasional diharapkan dapat menyelenggarakan program BIPA yang bertujuan untuk membekali Mahasiswa asing pengetahuan dan keterampilan berbahasa Indonesia. Penelitian ini bertujuan untuk mengetahui sikap belajar siswa terhadap program Bahasa Indonesia bagi Penutur Asing. Subjek penelitian ini adalah 3 mahasiswa asing asal Thailand yang sedang menempuh kuliah strata-1 di Universitas Muhammadiyah Kendari. Data dikumpulkan melalui wawancara dan observasi. Hasil dari penelitian ini menunjukkan bahwa siswa BIPA memiliki sikap belajar yang positif dalam berpartisipasi pada program BIPA. Mereka sangat antusias mengembangkan kemampuan bahasa Indonesia yang mereka miliki karena peran bahasa Indonesia sangat vital baik itu di dalam ataupun di luar kelas.
\end{abstract}

Kata Kunci: BIPA; Sikap; Antusias.

Abstract: Teaching Indonesian for Speakers of Other Language Program (BIPA) is a recommended Teaching program which is regulated by Government and Some particular Institution Indonesia. Muhammadiyah University of Kendari is one of universities that has international students is expected to be able to conduct BIPA Program which aims to educate foreign students with the knowledge and skills of Indonesian. This study aimed to determine student learning attitudes towards the Indonesian Language program for Other Speakers of Language. The subjects of this study were 3 foreign students from Thailand who were pursuing undergraduate studies at the Muhammadiyah University of Kendari. Data collected through questionnaire and observation. The results of this study indicate that BIPA students have positive learning attitudes in participating in the BIPA program. They were very enthusiastic in developing their Indonesian language skills because the role of Indonesian is very vital both inside and outside the classroom.

Keywords: BIPA; attitudes; Enthusiastic.

\section{PENDAHULUAN}

Pemelajar Bahasa Indonesia bagi Penutur Asing, merupakan mahasiswa asing asal Thailand, yang sedang kuliah di Universitas Muhammadiyah Kendari. Mahasiswa yang berasal dari Thailand ini merupakan mahasiswa yang diterima melalui jalur kerjasama Perguruan Tinggi Muhammadiyah (PTM) dengan Prince of Songhkla University (PSU) 
yang dipayungi Majelis Diktilitbang PP Muhammadiyah. Tujuan dari kerjasama ini merupakan untuk pengembangan universitas dalam menghadapi global competitiveness. Universitas Muhammadiyah Kendari merupakan salah satu universitas yang memiliki kesempatan untuk mendatangkan mahasiswa asing asal Thailand untuk belajar (kuliah) di Program Studi Bahasa Inggris. Untuk membantu mahasiswa Thailand memahami penjelasan dosen di kelas, mereka harus memilki kemampuan Bahasa Indonesia. Penguasaan Bahasa Indonesia menjadi kebutuhan mahasiswa tersebut karena perkuliahan memakai Bahasa Indonesia dan Bahasa Inggris.

Pusat Bahasa Universitas Muhammadiyah Kendari menjadi wadah pengajaran Bahasa Indonesia bagi Penutur Asing saat ini. Mahasiswa asing difasilitasi Program pembelajaran Bahasa Indonesia gratis. Program ini dilaksanakan 3 kali seminggu dengan lama waktu belajar 90 menit perhari. Mereka diajari oleh beberapa mentor baik dari Dosen Pendidikan Bahasa Inggris dan Guru yang disiapkan oleh Pusat Bahasa Universitas Muhammadiyah Kendari. Selain itu, Kantor Bahasa Provinsi Sulawesi Tenggara juga merupakan salah satu Lembaga yang memfasilitasi Program BIPA dalam hal pelatihan dan pengembangan Program BIPA, dan Bahan ajar.

Dalam prakteknya, pengajaran Bahasa Indonesia bagi Penutur Asing menemui beberapa tantangan hal ini dipengaruhi oleh beberapa faktor seperti Mahasiswa asing hanya menguasai Bahasa Thailand dan penguasaan Bahasa Inggris yang sangat minim, Mentor/guru yang memiliki masih minim pengalaman dalam program BIPA, waktu pembelajaran yang dilaksanakan di semester kedua dimana Mahasiswa Asing sudah mulai terfokus pada pembelajaran Bahasa Inggris. Dari beberapa uraian masalah yang telah disebutkan, Program pembelajaran BIPA bagi Mahasiswa Asing masih baru diaplikasikan sehingga butuh refleksi dari pemelajar agar menjadi rekomendasi untuk pengembangan program selanjutnya.

Dalam rangka pengembangan program Pembelajaran Bahasa Indonsesia bagi Penutur Asing (BIPA) di Universitas Muhammadiyah Kendari, Tim Peneliti bermaksud untuk mengetahui sikap belajar (attitude) mahasiswa Asing terhadap Program Bahasa Indonesia bagi Penutur Asing (BIPA) pada Unit Pelaksana Teknis (UPT) Bahasa Universitas Muhammadiyah Kendari. Sikap belajar merupakan hal penting karena dalam proses belajar siswa/mahasiswa Asing memiliki perasaan positif atau negatif, motivasi, emosional dan tingkah laku terhadap proses belajar yang mereka ikuti. Oleh karena itu, perlu diinvestigasi sikap belajar Mahasiswa Asing dalam Program Pembelajaran Bahasa Indonesia bagi Penutur Asing agar selanjutnya menjadi masukan untuk pengembanganpengembangan program selanjutnya.

Sikap belajar memiliki ciri-ciri tertentu, yaitu 1) arah sikap, merupakan afek yang membekas dirasakan terhadap suatu objek, dapat bersifat negatif atau positif; 2) drajat perasaan, merupakan drajat penilaian terhadap sesuatu objek tertentu dengan istilah baik dan buruk dengan kontinum berkisar dari arah negatif sampai positif (Newcomb et al, 1977:1981). Dalam hal ini, sikap belajar Mahasiswa Asing terhadap pembelajaran Bahasa Indonesia dipandang perlu untuk diketahui. Selanjutnya, aspek dari sikap adalah bagaimana emosional dan tingkah laku mereka terhadap pembelajaran BIPA itu sendiri. Esensi dari semuanya itu menyatakan bahwa sikap belajar terhadap Bahasa asing merupakan sikap yang dimiliki oleh para pemelajar bahasa. Hal ini baik yang dwibahasawan maupun yang multibahasawan terhadap suatu Bahasa. 


\section{METODE PENELITIAN}

Metode survey dengan skala likert digunkan dalam penelitian ini, yaitu dengan menyebar angket berbasis online kepada 3 mahasiswa asing. Metode likert scale survey adalah metode penelitian kuantitatif untuk mendapatkan data dari sekelompok manusia dengan pendekatan setuju/tidak setuju, puas/tidak puas, dan sebagainya tentang sikap, opini, tingkah laku, atau karakteristik dari mahasiswa asing sebagai partisipan dari penelitian ini. dalam jenis penelitian ini peneliti mengumpulkan data secara kuantitatif, data tersebut berupa; angket dan wawancara, dan data yang dianalisis secara statistik untuk menunjukan trend dari respon yang diberikan oleh populasi sasaran tentang fenomena yang dibahas. (Creswell, 2012). Data yang didapat dari angket tersebut disajikan dalam bentuk diagram untuk mengetahui kecenderungan sikap belajar mahasiswa terhadap program belajar Bahasa Indonesia bagi Penutur Asing (BIPA).

\section{HASIL PENELITIAN DAN PEMBAHASAN}

Berdasarkan hasil analisis data dalam penelitian ini, sikap mahasiswa asing terhadap program pembelajaran Bahasa Indonesia bagi Penutur Asing (BIPA) yang dilaksanakan di Universitas Muhammadiyah Kendari dapat dikatakan positif. Hal ini dapat diilustrasikan sebagai berikut:

Dari diagram, data menunjukkan bahwa sikap mahasiswa Thailand terhadap program pemebelajaran Bahasisa Indonesia bagi Penutur asing (BIPA) adalah positif. Hali ini ditunjukkan dengan antusiasme mereka ketika belajar pada program BIPA dilakukan dengan serius dan sepenuh hati.

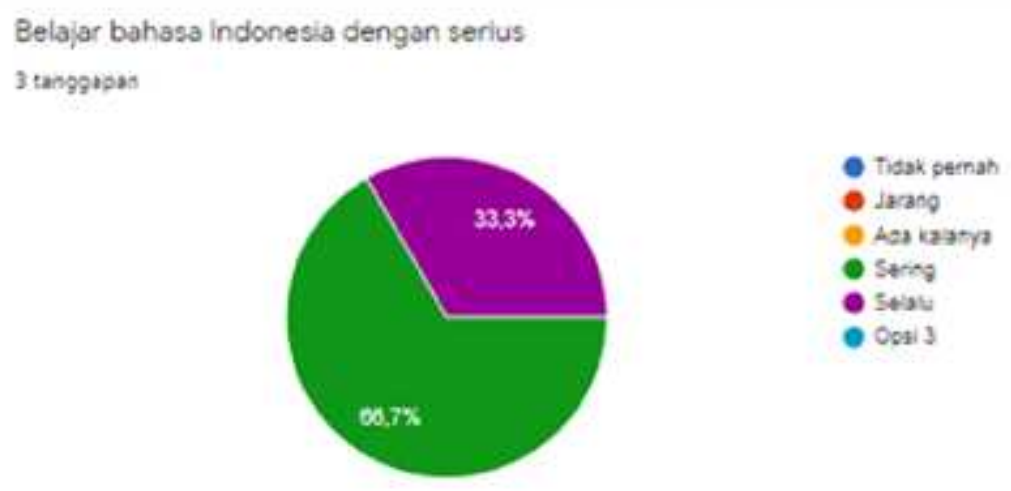

Gambar 1. Diagram Belajar Bahasa Indonesia Dengan Serius

Selanjutnya, fenomena kontradiktif dalam hal kebiasaan membaca. 2 dari 3 mahasiwa ada kalanya membaca modul/ materi yang diberikan. Hanya 1 mahasiswa yang sering membaca modul BIPA yang disediakan oleh pihak pengelola. 
Eaciariojis BIPA

Otarggepen

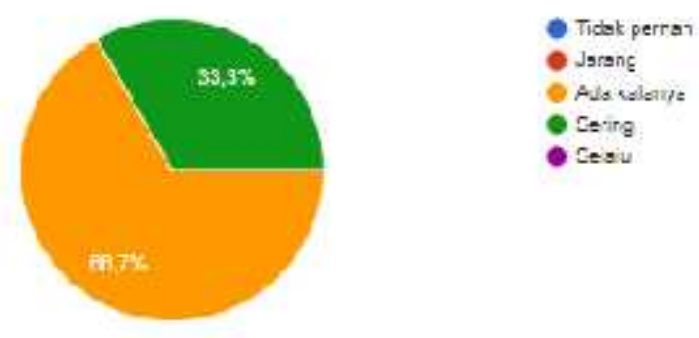

Gambar 2. Diagram Baca Modul BIPA

Di dalam proses belajar mengajar, masing-masing mahasiswa asing ini memiliki tingkah laku dalam mengajukan pertanyaan kepada mentor/guru. Dalam hal ini, 1 mahasiswa selalu bertanya, 1 menyatakan sering bertanya, dan agak berbeda dengan 2 mahasiswa yang lain. 1 mahasiswa hanya sesekali bertanya kepeda mentor.

Serius calam belajar

3 ismpuepat:

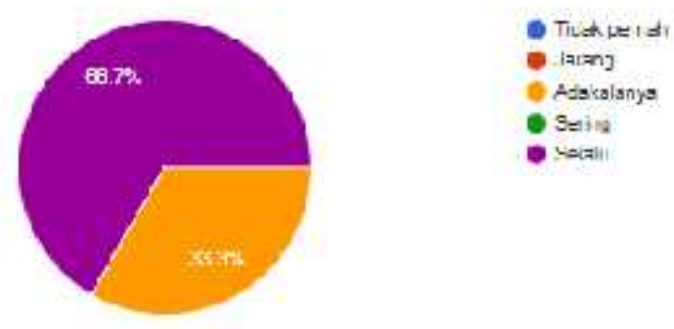

Gambar 3. Diagram Baca Modul BIPA

Mahasiswa asing UM Kendari ini memiliki antusiasme yang cukup tinggi. Hal ini didukung oleh perilaku mereka menunjukkan keseriusan dalam mengikuti program BIPA di UM Kendari.
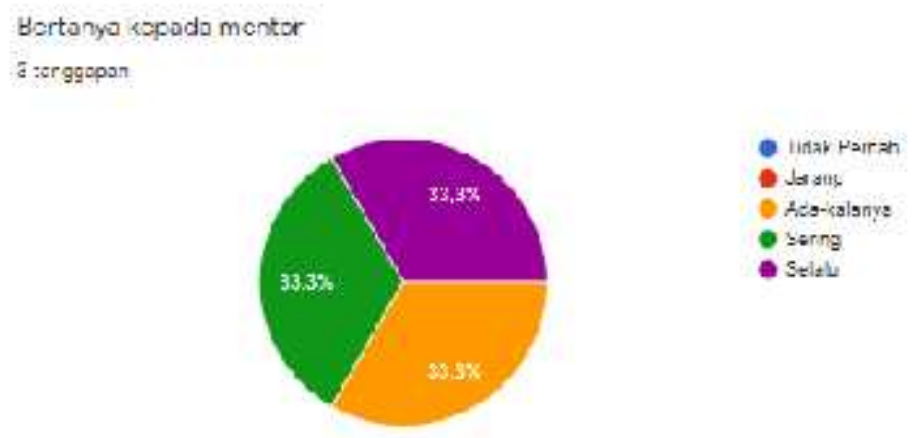

Gambar 4. Diagram Baca Modul BIPA 
Selain keseriusan yang cukup tinggi. Mahasiswa asing yang sementara mengikuti program BIPA juga selalu berupaya menggunakan bahasa Indonesia di dalam kelas BIPA. Hal ini menjadi program pembelajaran yang bermakna dimana mereka berupaya untuk selalu meningkatkan kemampuan mereka dalam berbahasa Indonesia.

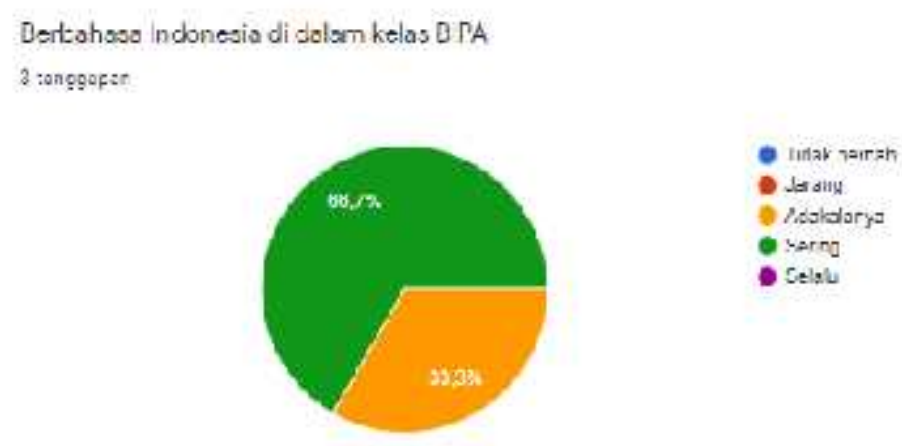

Gambar 5. Diagram Baca Modul BIPA

Hal yang tak kalah pentingnya juga adalah mahasiswa asing mereka selalu berupaya untuk datang tepat waktu ke kelas BIPA.

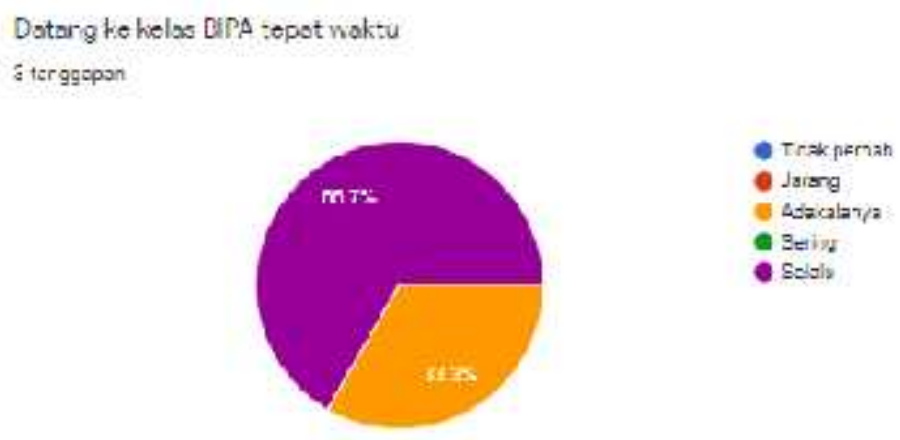

Gambar 6. Diagram Baca Modul BIPA

Selain berusaha mempraktekkan bahasa Indonesia di dalam kelas BIPA. Ketiga mahasiswa asing ini selalu berupaya berkomunikasi menggunakan bahasa Indonesia di luar kelas. Mereka berupaya untuk selalu berinteraksi dengan teman kelas yang berasal dari Indonesia dan mencoba memperlancar kemampuan bahasa Indonesia.

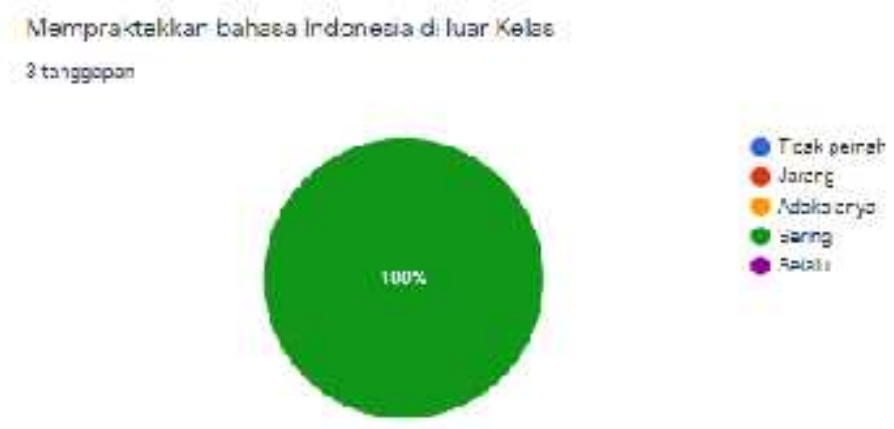

Gambar 7. Diagram Baca Modul BIPA 
Mahasiswa Thailand program BIPA yang sedang belajar di UM Kendari diharapkan mampu menguasai bahasa Indonesia yang baik dan benar. Terutama bagi mereka yang memasuki Program Studi Bahasa Inggris. Hal ini dilakukan karena bahasa Indonesia digunakan sebagai alat komunikasi utama antara pengajar dan pembelajar. Bahasa instruksional yang digunakan di dalam kelas bersifat bilingual (dwi bahasa) yakni bahasa Inggris dan Indonesia. Oleh karena itu, mahasiswa asing yang ingin belajar di UM Kendari sebaiknya menguasai menguasai bahasa Indonesia yang baik dan benar. Sikap dalam penelitan ini merujuk pada tingkah laku dalam situasi social/belajar tertentu. Berdasarkan temuan penelitian ini sikap mahasiswa Thailand terhadap Program Bahasa Indonesia bagi Penutur Asing (BIPA) di Universitas Muhammadiyah Kendari cenderung positif.

Salah satu hal yang mempengaruhi sikap mahasiswa Thailand program BIPA di UMKendari yakni proses pembelajaran yang diberikan kepada mereka. Jika dilihat dari pembelajaran BIPA di UM Kendari sendiri sudah keliahatan baik. Beberapa komponen penting dalam suatu proses pembelajaran dapat terpenuhi dengan baik. Sudah terdapat pengajar dari beberapa dosen yang turut membantu pengajaran BIPA khususnya bagi mereka yang paham dan sudah ahli dalam tata bahasa. Hanya saja, program ini perlu diperkuat oleh tenaga pengajar dari disiplin ilmu Pendidikan Bahasa Indonesia. Selain itu, adanya ruang kelas yang tetap atau dikhususkan dalam pembelajaran ini membuat mereka merasa nyaman belajar. Program BIPA yang difasilitasi oleh Pusat Bahasa UM Kendari menyediakan ruangan tersendiri dan cukup tenang untuk diadakan proses belajar mengajar. Akan tetapi, terkait hal yang perlu dikembangkan yakni kurikulum dari Program BIPA agar program tersebut dapat lebih terarah dan terukur.

Dari semua kelebihan dan kekurangan komponen pembelajaran tersebut, terjadi karena program BIPA di UM Kendari baru dirintis awal tahun 2019 ini. Sehingga masih banyak hal yang harus dibenahi untuk memajukan program BIPA di UM Kendari ini. Hal tersebut membutuhkan kerjasama yang baik dari semua elemen untuk mewujudkan program BIPA yang maju dan unggul.

\section{KESIMPULAN}

Sikap positif mahasiswa asing terhadap program pembelajaran Bahasa Indonesia bagi Penutur Asing (BIPA) di Universitas Muhammadiyah Kendari. Hal ini terlihat dipengaruhi oleh beberapa faktor yakni adanya motivasi yang bersifat instrumental yakni mereka diharapkan dapat menguasai bahasa Indonesia dikarenakan bahasa Indonesia merupakan bahasa yang digunakan dalam kelas selain bahasa Inggris, bahasa dalam melakukan kegiatan-kegiatan sosial baik itu dilingkungan dalam dan atau luar kelas, dan kehidupan sehari-hari. Olehnya itu, mereka cukup antusias dalam mengikuti program BIPA. Dari kesimpulan di atas tentang sikap mahasiswa terhadap Program Belajar BIPA (Bahasa Indonesia bagi Penutur Asing) dapat disimpulkan positif. oleh karena itu untuk meningkatkan kualitas Program Pengajaran belajar dalam program BIPA berupa (guru, fasilitas, dan waktu belajar) dan selajutnya maka diperlukan dukungan semua pihak. 


\section{UCAPAN TERIMA KASIH}

Penulis mengucapkan terima kasih kepada Lembaga Penelitian dan Pengabdian Kepada Masyarakat (LPPM), Universitas Muhammadiyah Kendari yang telah memberikan dukungan finansial dalam penelitian ini.

\section{DAFTAR PUSTAKA}

Brown, D. (2007). Prinsip Pembelajaran dan Pengajaran Bahasa. Jakarta: Kedutaan Besar Amerika Serikat.Hogg, M., \& Vaughan, G. (2005). Social Psychology (4th edition). London: Prentice-Hall.

Creswell, J. W. (2012). Educational research: Planning, conducting, and evaluating quantitative and qualitative research. Educational Research (Vol. 4). https://doi.org/10.1017/CBO9781107415324.0 04.

Kusmiatun, A. (2016). Mengenal BIPA (Bahasa Indonesia Bagi Penutur Asing) dan Pembelajarannya. Yogyakarta: K-Media.

McLeod, S. A. (2018). Attitudes and behavior. Retrieved from https://www.simplypsychology.org/attitudes.html.

Muliastuti, L. (2010). Pengembangan Materi Ajar Bahasa Indonesia Bagi Penutur Asing (BIPA). Disampaikan dalam Konferensi Internasional Pengajaran Bahasa Indonesia Bagi Penutur Asing, 29-31 Juli 2010 di Universitas Indonesia. 